\title{
A SINGULARIDADE DA MULHER CIGANA NA POESIA DE PAPUZCA
}

\author{
LA SINGULARIDAD DE LA MUJER GITANA EN LA POESÍA DE PAPUZCA
}

Isadora Paiva Espinosa ${ }^{1}$

Dulce Mari Silva Voss ${ }^{2}$

\begin{abstract}
Resumo: Este ensaio traz à tona a História de Papuzca, mulher cigana e poetisa, cuja existência e obra foi forjada em meio a resistência dos povos ciganos perseguidos em tempos de regime nazifascista. Percebe-se que essas manifestações culturais se mantêm vivas nos nossos dias, como mostra a preservação das danças e poesias ciganas na região da campanha gaúcha. Ao trazer aqui as afecções provocadas pelas manifestações culturais ciganas, especialmente a poesia de Papuzca, na linha de análise das filosofias de Deleuze e Guattari, pretende-se transpor a ideia de mulher como ser que se forma em oposição ao homem. Embora as desigualdades de gênero operem na captura dos corpos e essa mova a contestação das posições estabelecidas pelos movimentos decoloniais, os modos como sujeitos são produzidos e agenciados não dão contam de definir os corpos, as subjetividades e as existências. Cada existência é criação singular que acontece em devir.
\end{abstract}

Palavras-chave: Culturas ciganas; decolonilidade; devir-mulher.

Resumen: Este ensayo saca a la luz la historia de Papuzca, mujer gitana y poeta, cuya existencia y obra se forjó en medio de la resistencia del pueblo gitano perseguido en tiempos del régimen nazi-fascista. Se constata que estas manifestaciones culturales permanecen vivas en nuestros días, como demuestra la conservación de los bailes y la poesía gitana en la región de la campaña gaúcha. Al traer aquí los afectos provocados por las manifestaciones culturales gitanas, especialmente la poesía de Papuzca, en la línea de análisis de las filosofías de Deleuze y Guattari, se pretende transponer la idea de la mujer como un ser que se forma en oposición al hombre. Si bien las desigualdades de género operan en la captura de los cuerpos y esto mueve a la impugnación de las posiciones establecidas por los movimientos decoloniales, las formas en que se producen y actúan los sujetos no son suficientes para definir los cuerpos, las subjetividades y las existencias. Cada existencia es una creación singular que sucede en el devir. Palabras clave: Culturas gitanas; descolonización; devir-mujer.

Se o uno é pura ficção, invenção de máscaras que, reiteradamente, agem umas sobre as outras, transformando-as, sem que possamos encontrar o verdadeiro rosto escondido por trás delas, não há esse rosto, portanto, não há uma vida, não há um só corpo, mas, sim, multiplicidades de multiplicidades num jogo de afecções que movem e transfiguram corpos em forças que se atraem, chocam e tocam, compondo vidas.

Algumas dessas composições acontecem no ato de criação de poesias e danças, sejam essas do estilo que forem. Criação de intensa afecção, de paixão, que potencializa existências, invade os corpos e os faz transbordar. Quando poetizamos, quando dançamos, deliramos.

É por pensarmos e sentirmos assim que ensaiamos aqui a invenção da singularidade da mulher cigana que a história de Papuzca suscita em nós, como nos toca, nos afeta e move nossos pensamentos e sentimentos transfigurando-os nessa escrita. História de uma mulher cigana e

\footnotetext{
${ }^{1}$ Unipampa - Universidade Federal do Pampa.

${ }^{2}$ Unipampa - Universidade Federal do Pampa.
} 
poetiza forjada em meio a tantas outras histórias de povos ciganos que ainda hão de ser contadas, desdobradas em escritas que narrem suas existências e artes.

Artes que estão vivas nas danças ciganas e que são cultivadas e praticadas por muitos grupos e em vários espaços na cidade em que moramos, cidade situada na fronteira Brasil-Uruguai e que mantêm uma tradição de festivais internacionais de dança, como o Dança Bagé que ocorre anualmente, desde 2003. A forte presença das danças ciganas tem relação, entre outros fatores, com o povoamento aqui efetuado em que muitas famílias são originárias dos imigrantes árabes e configuram uma parcela expressiva da população sulina desde a colonização dessas terras.

Em termos históricos, a colonização europeia em regiões do oriente e do ocidente se deu pela imposição de um modelo civilizatório, perseguição, dizimação de outros povos e de seus modos de vida. Os grupos ciganos migravam de um lado para outro em razão das perseguições e preconceitos, o que acontece até os dias atuais. O nomadismo foi o modo como, por um longo tempo, resistiram e alguns ainda resistem ao modelo europeu civilizatório. Pensamos que o cultivo dos rituais e das artes ciganas é hoje outra forma de resistir ao padrão eurocêntrico. Linhas que vem se desenhando, abrindo fissuras e movendo fluxos imanentes no projeto da decolonialidade em ebulição. Decolonialidade que "tem se pautado na e pela produção de conhecimentos e experiências que pretendem romper com a imposição de modos de vida coloniais” (VOSS, 2020, p. 223).

Com isso, não estamos dizendo que exista uma cultura cigana pura e idealizada, pois não se trata de contrapor essa e aquela cultura e atribuir veracidade a qualquer que seja vista e anunciada com maior ou menor legitimidade. Mas, perceber que diferentes culturas coexistem e manifestam estilos de vida, costumes, crenças e pensamentos, tanto em sua organização interna, quanto em relação à outras coletividades (SILVA, 2006).

Atraídas pelas danças ciganas, acompanhamos alguns grupos que praticam estas artes em momentos como o dia 24 de maio, dia de Santa Sara, protetora dos ciganos e também nos festivais de final de ano. A alegria que expressam através das coreografias, do colorido dos figurinos e cenários que se misturam aos corpos e os desafazem no contágio dos movimentos que constituem corpos outros, é fascinante!
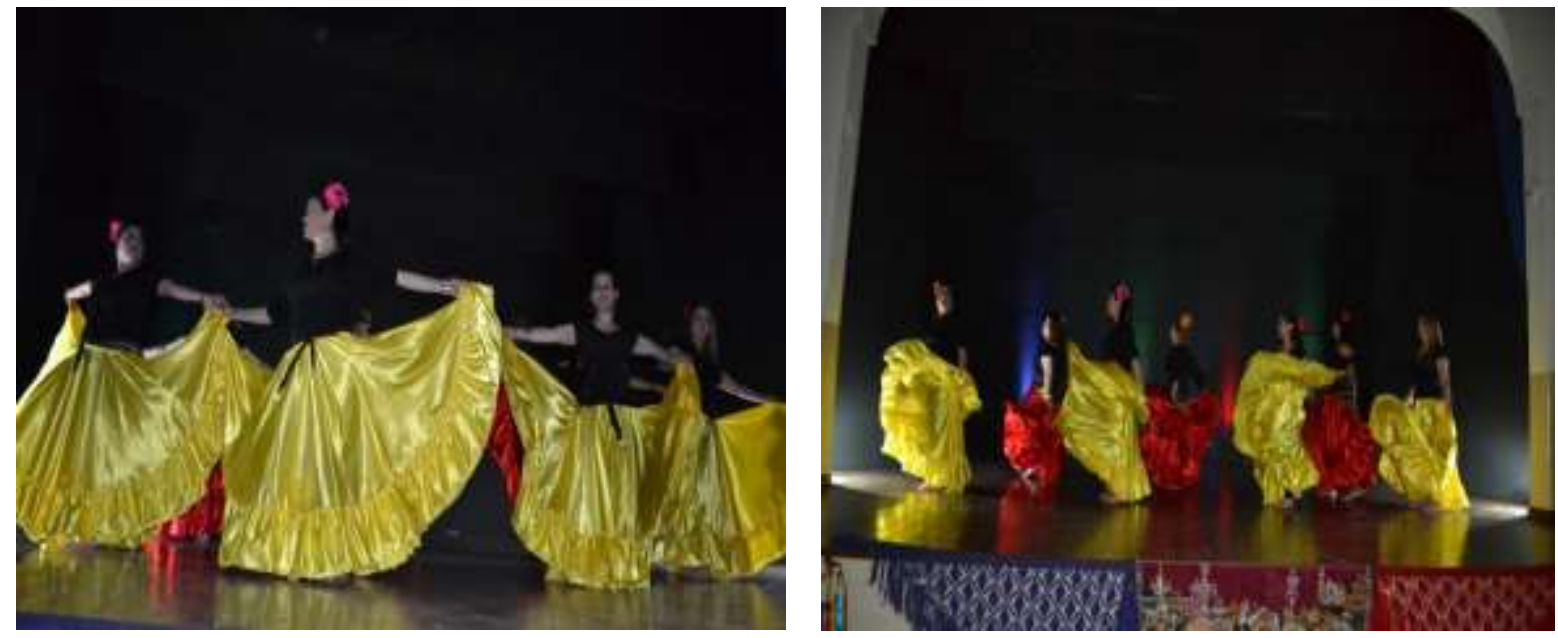

Imagens 01 e 02: V Festival Inspirarte - Que você seja abençoado com o sal, com o pão e com o ouro! Fonte: Autoras (2019)

Cada encontro de grupos de artistas e dançarinas/os ciganas/os tem uma temática inspiradora, sendo que a relação com a natureza é recorrente, uma vez que os povos ciganos 
produzem seus rituais e artes de existir em equilíbrio com os elementos terra, água, fogo e ar. Nos festivais também acontece a degustação de chás e pratos típicos.

Todas estas experimentações intensificam nosso prazer em conhecer e vivenciar as danças e poesias ciganas e pesquisar sobre elas. Por isso, a poetisa Papuzca nos encanta. Seu nome era Bronislawa Wajs, nasceu em 17 de agosto de 1908, em Lublin (Polônia), e faleceu em 8 de fevereiro de 1987 (MARTIN, 2015).

Mulher cigana que atravessou com coragem um período histórico extremamente adverso: a Segunda Guerra mundial (1939-1945), tempos em que vigoraram os regimes nazifascistas na Europa e que acarretaram o genocídio, além das populações judaicas, de comunistas, mulheres, crianças, negros, deficientes físicos e grupos ciganos.

Sabemos que ainda hoje as mulheres de diferentes culturas são silenciadas pela ordem heteronormativa, machista e patriarcal. Papuzca enfrentou essa barreira como mulher e numa cultura em que tal condição é ainda mais desafiadora. Assim, ao tornar-se poetisa, Papuzca rompeu com as restrições e determinações de sua época impostas aos povos ciganos e às mulheres ciganas. Ao inventar a singularidade de Papuzca experimentamos potências de criação através das leituras e vivências com manifestações culturais ciganas que são preservadas e transmitidas de geração em geração. Identificamo-nos com ela por sua força e coragem e por fazer da poesia sua máquina de guerra (CORREIA, 2013).

Pertencente a uma família arpista que transportava os grandes instrumentos em suas longas viagens do Norte das populações lituanas as Tatras orientais. Nessa vida nômade, Papuzca aprendeu a ler e escrever nos dias em que a Kumpania (uma espécie de banda cigana) parava, eram feitas trocas de galinha por lições e livros. Dessa forma, aos poucos ela foi criando uma pequena biblioteca que a acompanhava aonde ela fosse. Foi feito um grande esforço para efetivar a alfabetização, mesmo com a repressão que precisou enfrentar para seguir seus sonhos. Nos anos de 1920, um Rroma que soubesse ler e escrever era algo extremamente incomum.

Aos 15 anos, sua família a casou com um arpista mais velho que ela, tal fato não a agradou, motivo pelo qual ela não teve filhos. Foi quando começou a exercer a profissão de cantora. Isso despertou sua criatividade, iniciando assim a compor letras para as canções baseadas em sua tradição, o que serviu de meio de expressão de suas inquietações poéticas.

Ao longo da Segunda Guerra Mundial, Papuzca passou por mais uma barreira: perdeu mais de uma centena de familiares. Mas isso não fez com que desistisse e ainda pode perceber que grandes mudanças estavam por vir em sua cultura e tradições.

Porém, outros sentidos foram atribuídos aos poemas de Papuzca. Em 1950 apareceram alguns poemas publicados de Papuzca na revista Problemy juntamente com uma entrevista a Fikowski e uma tradução ao Rromaní da internacional comunista. Fikowski era um autor da obra considerada mais importante entre o povo judio e se tornou o assessor de Papuzca. Esse interesse surgiu porque ele percebeu que os poemas de Papuzca poderiam se instrumentalizar com fins propagandísticos entre os Rroma apoiando a política de sedentarização desenvolvida pelo governo Polaco com cerca de 15 mil ciganos sobreviventes do Holocausto.

Esse uso de seus poemas como instrumento propagandístico causou muitos problemas a Papuzca que recebeu uma visita de um grupo de emissários Rroma que a ameaçaram por considerala precursora dessa campanha. Na realidade, ela foi usada e mal interpretada. Tentou recuperar a sua obra e autoria mas foi rejeitada pelo Sindicato de Escritores Polacos, também tentou impedir a publicação de um livro de Fikowski no qual havia alguns poemas seus. A publicação desse livro traria a intervenção da justiça Rroma que a declarou impura e a expulsou do grupo. Essa expulsão irreversível resultou em sua internação em um centro psiquiátrico durante oito meses.

Os 34 anos que ela ainda viveu foi sozinha e em completo isolamento sendo evitada por sua geração e desconhecida pela seguinte. Somente no final dos anos 60 alguns poemas seus 
reapareceram. A Fikowski se considera um traidor, apesar de reconhecer seu trabalho acadêmico e que por seu trabalho seguem conservando alguns poemas de Papuzca, como o que transcrevemos a seguir:

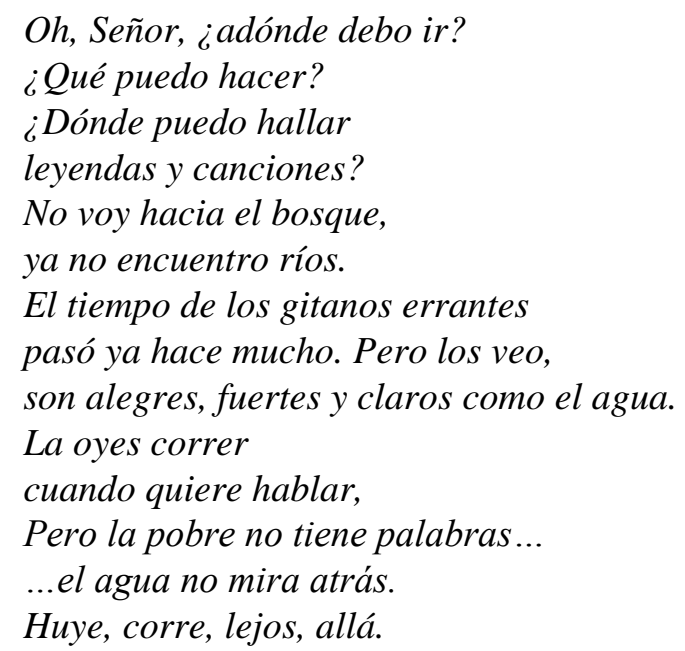

Nele percebemos a força da poesia de Papuzca que num jogo de palavras e versos entrelaça movimentos de vida errante dos povos ciganos, misturados a elementos da natureza, bosques, rios, águas, e às tradições expressas em lendas e canções, multiplicidades de multiplicidades. Poetizar resistências!

Ao mergulhar nos estudos da filosofia de Deleuze e Guattari (2012), percebemos que, na experimentação da poesia, Papuzca devem mulher cigana. Mulher em processo, em movimento de inacabamento, assim sendo, ao devir mulher poetisa faz-se possível burlar regulações, medos, dores, nascimentos e mortes:

Devir não é certamente imitar, nem identificar-se; nem regredir-progredir; nem corresponder, instaurar relações correspondentes; nem produzir, produzir uma filiação, produzir por filiação. Devir é um verbo tendo toda sua consistência; ele não se reduz, ele não nos conduz a "parecer", nem "ser", nem "equivaler", nem "produzir" (DELEUZE; GUATTARI, 2012, p. 20).

Cada mulher pode devir mulher, pois, as mulheres, enquanto "devir-minoritário", apresentam maiores condições de transformação das subjetividades, já que não constituem o polo central de poder que se traduz na forma homem. Daí o entendimento de que: “[...] a sexualidade passa pelo devir-mulher do homem e pelo devir-animal do humano" (DELEUZE; GUATTARI, 2012, p. 75).

E isto não consiste em delinear um ser mulher, ou uma ontologia do gênero, mas pensar por multiplicidades, vazios a não serem preenchidos, mas sentidos e potencializados. Devir mulher é potência que, em Papuzca se realiza por meio da poesia, pois: "É preciso antes que a escrita produza um devir-mulher, como átomos de feminilidade capazes de percorrer e de impregnar todo um campo social" (DELEUZE; GUATTARI, 1997, p. 72).

Devir-mulher como chave para a criação de novos modos de existência. As mulheres. Portanto, devir-mulher não é uma cópia de formas determinadas dos conjuntos molares. Não nos tornamos "como" uma mulher, uma criança ou um animal. Todo devir nunca é devir alguma coisa exterior e pré-estabelecida, conformar-se a um modelo ou fazer algo proporcional a ele. Devimos outra coisa quando experimentamos a desterritorialização das formas e substâncias preestabelecidas como naturais. 
Deleuze e Guattari (2012, p. 74) apontam que "todos os devires começam e passam pelo devir-mulher". Nem imitar, nem tomar a forma feminina, mas emitir partículas que entrem na zona de vizinhança de uma microfeminilidade. Isto é, produzir em nós mesmos uma mulher molecular. Criar a mulher molecular em homens e mulheres (DELEUZE; GUATTARI, 2012).

A escrita é inseparável do devir; ao escrever, experimentamos devires, devir-animal ou vegetal, devir-molécula, devir imperceptível, uma passagem de vida, que atravessa o vivível e o vivido. Escrever é, portanto, entrar em estado de devir, sempre inacabado, sempre em vias de fazer-se, e que extravasa qualquer matéria vivível ou vivida.

Movendo-se da oralidade para a escrita, Papuzca escapa da ordem colonial e patriarcal que agencia os corpos e as existências de mulheres ciganas. Devem poetisa, fazendo da escrita a linha de fuga para forjar sua existência singular (DIAS, 2007).

\section{Referências}

CORREIA, Paulo Petronilio. Poesia: a "máquina de guerra" do pensamento. Revista Texto Digital, v. 09, n. 01, Florianópolis, SC, jan./jul. 2013, p. 68-94. Disponível em: https://periodicos.ufsc.br/index.php/textodigital/article/view/1807-9288.2013v9n1p68. Acesso em: 23 de setembro de 2020.

DELEUZE, Gilles; GUATTARI, Félix. Mil Platôs: Capitalismo e esquizofrenia 2. v. IV. Tradução Suely Rolnik. São Paulo: Editora 34, 2012.

DIAS, Sousa. "Partir, evadir-se, traçar uma linha": Deleuze e a literatura. Revista Eletrônica PUC/RS, n. 02 (62), Porto Alegre, RS, maio/ago. 2007, p. 277-285. Disponível em: https://revistaseletronicas.pucrs.br/ojs/index.php/faced/article/view/558/388. Acesso em: 23 de setembro de 2020.

MARTIN, Pedro Moral. Papuzca: la primera poetisa gitana. 2015. Disponível em: http://eldiario.es/cultura/cine/papusza-gitana-condenada-talento_1_2519581.html. Acesso em: 20 de setembro de 2020.

SILVA, Valéria Sanchez. Devir Cigano: O encontro cigano - não-cigano (rom-gadjé) como elemento facilitador de individuação, 2006. Dissertação (Mestrado em Psicologia Clínica) Pontifícia Universidade Católica de São Paulo, São Paulo, 2006. Disponível em: http://livros01.livrosgratis.com.br/cp008824.pdf. Acesso em: 20 de setembro de 2020.

VOSS, Dulce Mari da Silva. Habitar outros mundos em tempos sombrios. In: ROCHA, Paulo Henrique B.; MAGALHÃES, José Luiz Q.; OLIVEIRA, Patrícia Miranda P. Decolonialidade a partir do Brasil. v. 01. Belo Horizonte: Editora Dialética, 2020. p. 221-240.

\section{Sobre as autoras}

Isadora Paiva Espinosa. Graduanda em Letras Línguas Adicionais Inglês e Espanhol e suas Respectivas Literaturas na Universidade Federal do Pampa, Campus Bagé (RS); membro do Grupo de Pesquisa Philos Sophias (CNPQ); Lattes: http://lattes.cnpq.br/5828564188843611; E-mail: isadoraespinosa.aluno@unipampa.edu.br. 
Dulce Mari Silva Voss. Doutora em Educação; Docente da Universidade Federal do Pampa, Campus Bagé (RS); Líder do Grupo de Pesquisa Philos Sophias (CNPQ); Lattes: http://lattes.cnpq.br/6357471301897496; E-mail: dulcevoss@unipampa.edu.br. 